\title{
ABOUT THE RESULTS OF THE DESTRUCTION OF THE MOLECULES OF LIQUID HYDROCARBONS IN THE FIELD OF ACOUSTIC CAVITATION
}

\author{
Michael Rudenko, ${ }^{1,}$, Mark Vasiltsov ${ }^{1}$, Stepan Gorbasenko ${ }^{1}$, and Tatiana Lavrenyuk ${ }^{1}$ \\ ${ }^{1}$ Angarsk State Technical University, Angarsk, Russia
}

\begin{abstract}
Analysis was conducted of fractional composition of hydrocarbon fuel. It is found that the excitation of cavitation in the fuel leads to a change of its fractional composition. This result can be explained by the destruction of liquid hydrocarbon molecules under high intensity of the unsteady pressure field
\end{abstract}

\section{Introduction}

To intensify the process, which is conducted in liquid, various methods are used, including cavitation. In [1], Professor Ivchenko V.M. highlighted the main hydrodynamic phenomena accompanying the collapse of the cavitation bubble. Firstly, it is the emergence of shock waves with an intensity of up to $100 \mathrm{MPa}$; forming streams 30-70 microns in diameter and up to $200 \mathrm{~m} / \mathrm{s}$; unsteady pressure fields of different frequency band from the collapsing bubbles.

More recent studies have shown the feasibility of processing the fuel-water mixture in the field hydrodynamic cavitation $[2,3]$.

The data obtained is determine the interest to possible changes in the molecular composition of a liquid hydrocarbon fuel when it is processed in conditions the nonstationary pressure fields of high intensity.

In experiments [4] it was found that:

- when exposed to ultrasonic cavitation on hydrocarbon $\left(\mathrm{C}_{9} \mathrm{H}_{20}\right)$ free radicals are formed;

- colliding with molecules of the original fuel, the free radicals is generated formation of new radicals;

\footnotetext{
Corresponding author: $\underline{\text { mg-rud@mail.ru }}$
} 
- in products of reaction accumulate in hydrocarbons of lower molecular weight.

Decrease in molecular weight may be a special case, which is typical for the experimental conditions, or used hydrocarbon.

In this connection, was conducted an experiment to determine the fractional composition of the base diesel fuel (without additives) before and after exposure acoustic cavitation.

\section{A brief description of the equipment and technology of the experiment}

In experiments using a device of ultrasonic technology UZTA-0.8 / 22 with a frequency of $\approx 22 \mathrm{kHz}$

Fuel test sample of $100 \mathrm{ml}$ was placed in a sealed reactor made of stainless steel

When acoustic radiation imposed on the fuel, its temperature is increased, resulting in the need to use a cooling and controlling the temperature using a thermocouple.

Distillation of diesel fuel before and after cavitation,was carried out in accordance with GOST 2177-82, using standard equipment.

\section{Results of experiment}

The results of measurements of fractional composition of diesel fuel before and after the cavitation effects are presented in figure 1, where the horizontal axis represents the value of the percentage composition of the fractionated fuel, and the vertical axis represents the temperature of boiling of the appropriate fractions. Markers "plus" correspond to the control sample. The samples treated in the field of acoustic cavitation, corresponds to a " $\mathrm{X}$ " mark.

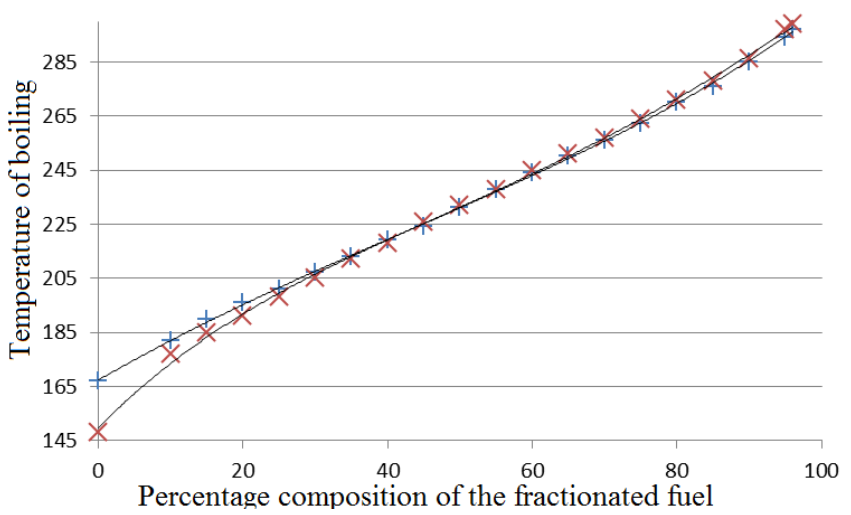

Fig. 1. The boiling points of the control sample and the treated diesel fuel.

The part of the experimental data, and the nature of the dependencies obtained prior to treatment and after fuel treatment in the field of acoustic cavitation is coincide, making it difficult to analyze the results. 
Consider the difference between the boiling temperatures of the appropriate fractions (see. figure 2).

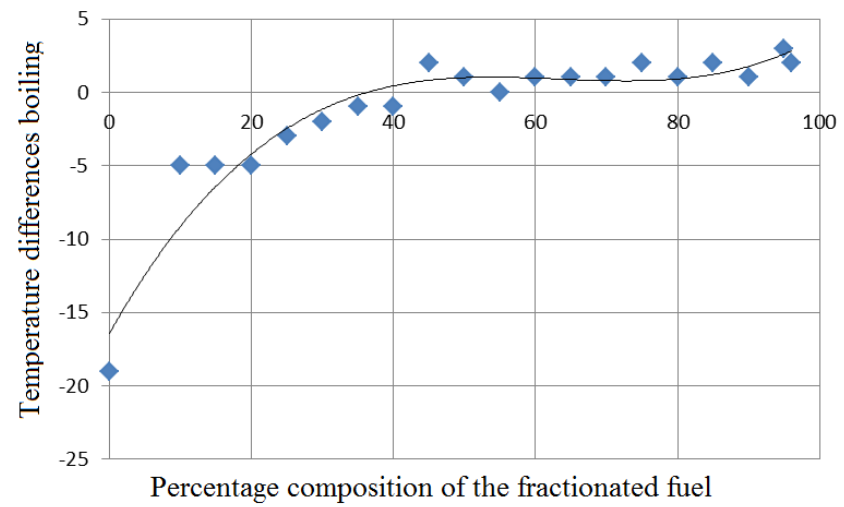

Fig. 1. Temperature differences boiling of experimental and control samples of the diesel fuel.

\section{Discussion of the results}

Note the following features:

- as a result of cavitation, distillation temperature of the light ends somewhat reduced. This may indicate the formation of hydrocarbons with lower molecular weights than the original fuel.

- Simultaneously with decreasing temperature of distillation light ends, there is a slight increase of temperature factions of high-boiling components of the diesel fuel. This may indicate the formation of hydrocarbons with a higher molecular weight than the original fuel.

We assume that the marked differences can be explained as follows:

- under acoustic cavitation occurs formation of radicals, which agrees with previous data and

- as a result of transformation, hydrocarbons accumulate with a higher and a lower molecular weight

\section{References}

1. V.M. Ivchenko, E.D. Malimon, Prilkladnaya mechanica I teplophisica [Applied Mechanics and Thermophysics] 5 (1975) [in Russian]

2. M.G. Radchenko, V.I. Grintsevich Hydrodynamica bol'shih scorostey: mejvusovskiy sbornik (Hydrodynamics of high speeds: Interuniversity collection, 1982) [in Russian]

3. V.M. Ivchenko, M.G. Rudenko, N.G. Rudenko, Sposop obrabotky topliva dvigateley vnutrennego sgoraniya (Internal combustion engines fuel processing method of the copyright certificate) USSR No.125419 [in Russian]

4. S.P. Zubrilov, V.I. Seliverstov, M.I. Braslavsky, LIVT Trudy 45 (1982) [in Russian] 